\title{
Influence of luminance on hemispheric processing
}

\author{
JUSTINE SERGENT \\ McGill University, Montreal, Quebec H3A 1B1, Canada
}

\begin{abstract}
The influence of stimulus energy on the respective processing efficiency of the cerebral hemispheres was examined by varying the luminance of the display. Twelve right-handed males were laterally presented with faces to categorize as "female" or "male." The stimulus luminance was $.8 \mathrm{~mL}$ in one session and $12 \mathrm{~mL}$ in another, and all other methodological variables were held constant. A significant interaction between luminance and visual field was observed, resulting from an improved efficiency of the left hemisphere with an increase in luminance. The results are interpreted in terms of a differential sensitivity of the hemispheres to stimulus energy and, consequently, to the spatial frequency spectral components of the incoming information.
\end{abstract}

A recent series of experiments examined the influence of exposure duration on hemispheric processing efficiency in a facial categorization task (Sergent, 1982). A shift from left-visual-field (LVF) to right-visual-field (RVF) advantage was observed as exposure duration increased, a finding similar to that obtained by Bradshaw, Hicks, and Rose (1979) and by Pring (1981) in a lexical discrimination task. These results were interpreted as showing a differential hemispheric sensitivity to stimulus energy and, consequently, to spatial frequency spectral components, although the duration over which energy is integrated was also found to contribute to the respective efficiency of the hemispheres.

Increasing exposure duration while keeping luminance constant results in an increase in stimulus energy as long as the presentation time is below the critical duration over which the time-intensity reciprocity holds (Bloch's law). This critical duration is on the order of 300$400 \mathrm{msec}$ in spatial acuity tasks (Kahneman, 1964), and thus, well above the maximum duration usually employed in lateralized tachistoscopic presentations. Thus, if stimulus energy is an important factor in determining the relative superiority of one hemisphere over the other, varying luminance while keeping exposure duration constant should result in a shift in visualfield advantage similar to that observed when only exposure duration is manipulated.

The present study sought to examine this prediction by using the same task, stimuli, procedure, and equipment used in the experiments on the influence of exposure duration (Sergent, 1982). In the first of these experiments, it was observed that, at $120-\mathrm{msec}$ exposure and $3-\mathrm{mL}$ luminance, equal latencies were obtained in the two visual fields. Since the purpose of the present study was to examine relative hemispheric efficiency as a function of luminance-dependent energy rather than to determine an absolute level of energy at which a shift in visual-field superiority would occur, a 120 -msec exposure was used and luminance was set at four times either above or below $3 \mathrm{~mL}$ (i.e., $12 \mathrm{~mL}$ and $.8 \mathrm{~mL}$ ). Although this more than tenfold increase in luminance may appear quite large, it is far less than the range of luminance values used in visual laterality studies. For example, among the experiments based on Posner's (1969) paradigm, one by Hellige and Webster (1981) used .32-mL luminance and another by Simion, Bagnara, Bisiacchi, Roncato, and Umiltà (1980) was conducted with a 173-mL luminance. Interestingly enough, the former experiment yielded an LVF advantage in both physically identical and name-identical matches, whereas the latter produced an RVF superiority in both types of matches, which is consistent with the present prediction. However, these luminance values are certainly not sufficient to account for such results (quite different exposure durations were also used), but, considering that a visual-field superiority may be overdetermined by a multitude of factors (Sergent, 1982), the luminance variable may have contributed to the particular pattern of results of these two experiments.

\section{METHOD}

Except for the luminance and exposure variables, the method of this experiment was in all points identical to that of the previous experiments (Sergent, 1982), and it will be only briefly presented.

The stimuli were black-and-white photographs of 10 male and 10 female faces unknown to the subjects. The faces were presented $3 \mathrm{deg}$ to the right or left of fixation, and they subtended a visual angle of $3 \mathrm{deg}$. They were rear-projected through a random-access projector on a translucent screen whose luminance was kept constant at $3 \mathrm{~mL}$. Each photograph was presented four times in each visual field, giving a total of 160 trials/ session, trials on which an error was made being repeated later in the sequence. The subject's task was to press a Morse key if the face was a female and another key if it was a male; the responding hand was counterbalanced across subjects.

The subjects participated in two experimental sessions performed under different viewing conditions. In one session, the 
test luminance was $.8 \mathrm{~mL}$, and in the other, $12 \mathrm{~mL}$. Exposure duration was kept at $120 \mathrm{msec}$ in both sessions. The order of viewing conditions was counterbalanced within each respondinghand group.

The subjects were 12 males (age ranging between 19 and 28 years), drawn from an unemployment agency, and they were paid for their participation. They were all right-handed, with no history of familial sinistrality, and with normal or correctedto-normal acuity. Handedness was assessed with Oldfield's (1971) questionnaire and a hand-tapping task.

\section{RESULTS}

Correct response latencies, averaged across subjects, were analyzed through a four-way analysis of variance. There were two between-subjects factors, hand responding and order of condition, the latter nested within the former. The two within-subjects factors were luminance and visual field. The results are presented in Table 1 as a function of the two within-subjects variables.

The only main effect to reach a reliable level of significance was that of order of condition $[F(1,8)=$ $8.37, \mathrm{p}<.05]$. Subjects who were given the highluminance condition first had shorter latencies overall than subjects starting with the low-luminance condition (517 msec and $562 \mathrm{msec}$, respectively). This factor did not significantly interact with any of the other variables. Subjects responded faster in the high- than in the lowluminance condition (525 $\mathrm{msec}$ and $554 \mathrm{msec}$, respectively), but this difference was not significant $[\mathrm{F}(1,8)=$ $4.88, \mathrm{p}>.05]$.

The interaction between luminance and visual field, illustrated in Table 1 , was significant $[F(1,8)=9.99$, $\mathrm{p}<.05]$. As was the case when exposure duration was manipulated (Sergent, 1982), this interaction resulted from an improvement in RVF performance as luminance was varied from low to high, whereas LVF performance remained essentially unchanged at both luminance values. No other interaction approached significance.

The error rate was $4.72 \%$. The same effect of order of presentation as in the analysis of latencies was observed $(\mathrm{p}<.05)$, and this was the only effect to reach a reliable level of significance in the analysis of errors. The effect of luminance did not even approach significance $(p>.20)$, and this seems to be consistent with psychophysical findings showing that, except at very brief exposure (less than $16 \mathrm{msec}$ ), weak luminance affects

Table 1

Mean Latencies (in Milliseconds) and Standard

Deviations in the Left and Right Visual

Fields as a Function of Luminance

\begin{tabular}{ccc}
\hline & Mean & SD \\
\hline & Low Luminance \\
LVF & 536 & 40 \\
RVF & 572 & 57 \\
& High Luminance & \\
LVF & 539 & 42 \\
RVF & 511 & 40 \\
\hline
\end{tabular}

response latency but not response accuracy (Kaswan \& Young, 1965).

\section{DISCUSSION}

The present results provide further support to the suggestion that the cerebral hemispheres may not require similar levels of energy to engage in cognitive processing and to operate efficiently. The left hemisphere was found to benefit more than the right hemisphere from an increase in luminance-dependent energy, in a manner similar to that observed when energy was manipulated through manipulation of exposure duration (Sergent, 1982) or retinal eccentricity (Sergent, Note 1). One of the consequences of this differential hemispheric activation threshold and sensitivity concerns the nature of the information on which each hemisphere may preferentially operate. For the right hemisphere to be able to process the information received at low stimulus energy better than the left hemisphere, it must be equipped to deal with the low spatial frequency spectral components that are essentially available in such conditions. On the other hand, the improved performance of the left hemisphere with increased energy may imply that this hemisphere must be better equipped than the right hemisphere to process high spatial frequency components. This suggests that, while stimulus energy affects the overall efficiency of the brain, information may be represented differentially in the two hemispheres.

Besides the obvious methodological implications of the present results and the need for controlling luminance in visual laterality studies, it may be suggested that a greater sensitivity to low energy may underlie the predominant right-hemisphere mediation of attentional processes (Heilman \& van den Abell, 1980). In support of this suggestion is the evidence that, in newborn humans, only the right hemisphere may be activated by flashes of light (Crowell, Jones, Kapunia, \& Nakagawa, 1973). This view may also offer the possibility to understand the brain as a single organism whose hemispheres operate in phase by processing different aspects of the same information.

\section{REFERENCE NOTE}

1. Sergent, J. State limitations in hemispheric processing. Manuscript submitted for publication, 1982.

\section{REFERENCES}

Bradshaw, G. J., Hicks, R. E., \& Rose, B. Lexical discrimination and letter-string identification in the two visual fields. Brain and Language, 1979, 8, 10-18.

Crowell, D. H., Jones, R. H., Kapunia, L. E., \& Nakagawa, J. K. Unilateral cortical activity in newborn humans: An early index of cerebral dominance? Science, 1973, 180, 205-208.

Heilman, K. R., \& van den Abell, T. Right-hemisphere dominance for attention: The mechanism underlying hemispheric asymmetries of inattention (neglect). Neurology, 1980, 30, 327 330.

Hellige, J. B., \& Webster, R. Case effects in letter-name matching: A qualitative visual field difference. Bulletin of the Psychonomic Society, 1981, 17, 179-182.

KahNEman, D. Temporal summation in an acuity task at different energy levels-A study of the determinants of summation. Vision Research, 1964, 4, 557-566.

KAswan, J., \& Young, S. Effect of luminance, exposure duration and task complexity on reaction time. Journal of Experimental Psychology, 1965, 69, 385-394.

OldFiELD, R. C. The assessment and analysis of handedness: The Edinburgh inventory. Neuropsychologia, 1971, 9, 353-383.

Posner, M. I. Abstraction and the process of recognition. In G. Bower \& J. T. Spence (Eds.), The psychology of learning and motivation. New York: Academic Press, 1969. 
Pring, T. R. The effects of stimulus size and exposure duration on visual field asymmetries. Cortex, 1981, 17, 227-240.

Sergent, J. Theoretical and methodological consequences of variations in exposure duration in visual laterality studies. Perception \& Psychophysics, 1982, 31, 451-461.

Simion, F., Bagnara, S., Bisiacchi, P., Roncato, S., \&
UMILTÀ, C. Laterality effects, levels of processing, and stimulus properties. Journal of Experimental Psychology: Human Perception and Performance, 1980, 6, 184-195.

(Received for publication August 8, 1982.) 